\title{
Crystal structure of $\left(2,2^{\prime}\right.$-bipyridyl)bis (4-chlorobenzyl)dichloridotin(IV), $\mathrm{C}_{24} \mathrm{H}_{20} \mathrm{Cl}_{4} \mathrm{~N}_{2} \mathrm{Sn}$
}

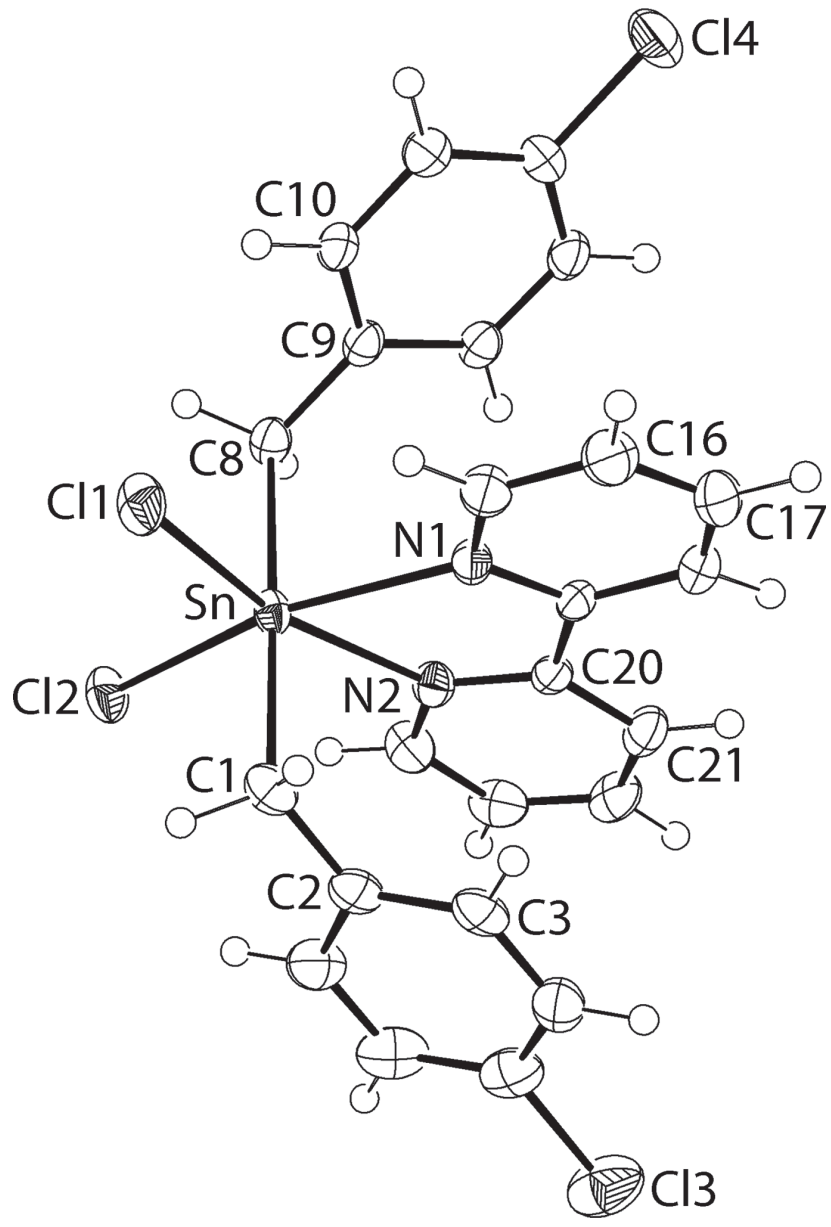

https://doi.org/10.1515/ncrs-2019-0508

Received July 18, 2019; accepted August 21, 2019; available online September 9, 2019

\section{Abstract}

$\mathrm{C}_{24} \mathrm{H}_{20} \mathrm{Cl}_{4} \mathrm{~N}_{2} \mathrm{Sn}$, monoclinic, $P 2{ }_{1} / n$ (no. 14), $a=7.7944$ (1) $\AA$, $b=21.1245(2) \AA, \quad c=14.7611(1) \AA, \quad \beta=95.077(1)^{\circ}$,

\footnotetext{
*Corresponding author: Edward R.T. Tiekink, Research Centre for Crystalline Materials, School of Science and Technology, Sunway University, 47500 Bandar Sunway, Selangor Darul Ehsan, Malaysia, e-mail: edwardt@sunway.edu.my. https://orcid.org/0000-00031401-1520

See Mun Lee and Kong Mun Lo: Research Centre for Crystalline Materials, School of Science and Technology, Sunway University, 47500 Bandar Sunway, Selangor Darul Ehsan, Malaysia
} $V=2420.92(4) \AA^{3}, Z=4, R_{\mathrm{gt}}(F)=0.0229, w R_{\mathrm{ref}}\left(F^{2}\right)=0.0603$,
$T=100(2) \mathrm{K}$.

CCDC no.: 1948401

The molecular structure is shown in the figure. Table 1 contains crystallographic data and Table 2 contains the list of the atoms including atomic coordinates and displacement parameters.

Table 1: Data collection and handling.

\begin{tabular}{ll}
\hline Crystal: & Colourless prism \\
Size: & $0.14 \times 0.09 \times 0.04 \mathrm{~mm}$ \\
Wavelength: & Cu $K \alpha$ radiation $(1.54178 \AA)$ \\
$\mu:$ & $12.6 \mathrm{~mm}^{-1}$ \\
Diffractometer, scan mode: & XtaLAB Synergy, $\omega$ \\
$\theta_{\max }$, completeness: & $67.1^{\circ},>99 \%$ \\
$N(h k l)_{\text {measured }}, N(h k l)_{\text {unique }}, R_{\text {int }}:$ & $30103,4329,0.042$ \\
Criterion for $I_{\text {obs }}, N(h k l)_{\mathrm{gt}}:$ & $I_{\text {obs }}>2 \sigma\left(I_{\text {obs }}\right), 3987$ \\
$N(\text { param })_{\text {refined }}:$ & 280 \\
Programs: & CrysAlis \\
& WinG $[1]$, SHELX $[2,3]$, \\
&
\end{tabular}

\section{Source of material}

The melting point of the compound was measured on a Melt-Temp II digital melting point apparatus and was uncorrected. The IR spectrum was measured on a Bruker Vertex 70v FTIR spectrophotometer from 4000 to $400 \mathrm{~cm}^{-1}$. The ${ }^{1} \mathrm{H}$ and ${ }^{13} \mathrm{C}\left\{{ }^{1} \mathrm{H}\right\}$ NMR spectra were recorded in $\mathrm{CDCl}_{3}$ solution on a Bruker Ascend $400 \mathrm{MHz}$ NMR spectrometer with chemical shifts relative to tetramethylsilane.

Di(4-chlorobenzyl)tin dichloride was synthesized by the direct reaction of 4-chlorobenzyl chloride (Aldrich) and metallic tin powder (Merck) in toluene according to a literature procedure [5]. Di(4-chlorobenzyl)tin dichloride (0.44 g, $1.0 \mathrm{mmol}$ ) and 2,2'-bipyridine (Aldrich, $0.16 \mathrm{~g}, 1.0 \mathrm{mmol}$ ) were heated in $95 \%$ ethanol $(30 \mathrm{~mL})$ and stirred for $2 \mathrm{~h}$. After filtration, the filtrate was evaporated slowly until colourless crystals were formed. Yield: $0.31 \mathrm{~g}$ (51.9\%). M.pt: 471-473 K. IR $\left(\mathrm{cm}^{-1}\right): 1606(\mathrm{~m}) v(\mathrm{C}-\mathrm{N})$, 1483, $1141(\mathrm{~s}) v(\mathrm{C}-\mathrm{N}), 481(\mathrm{~m})$ $v(\mathrm{Sn}-\mathrm{N}) .{ }^{1} \mathrm{H}$ NMR $\left(\mathrm{CDCl}_{3}, \mathrm{ppm}\right): \delta 3.17\left(\mathrm{~s}, 2 \mathrm{H}, \mathrm{Ph}-\mathrm{CH}_{2}\right)$, 6.55-6.56 (dd, 2H, Ph-H), 6.57-6.58 (dd, 2H, Ph-H), 7.50-7.73 (m, 1H, bipy-H), 7.86-7.88 (d, 1H, bipy-H), 8.03-8.07 (t, 1H, 
Table 2: Fractional atomic coordinates and isotropic or equivalent isotropic displacement parameters $\left(\AA^{2}\right)$.

\begin{tabular}{|c|c|c|c|c|}
\hline Atom & $x$ & $y$ & $z$ & $U_{\text {iso }} * / U_{\text {eq }}$ \\
\hline Sn & $0.56304(2)$ & $0.69771(2)$ & $0.57470(2)$ & $0.02011(6)$ \\
\hline $\mathrm{Cl} 1$ & $0.65370(8)$ & $0.76490(3)$ & $0.71076(4)$ & $0.03300(14)$ \\
\hline $\mathrm{Cl} 2$ & $0.46362(8)$ & $0.59790(3)$ & $0.64596(4)$ & $0.03040(14)$ \\
\hline $\mathrm{Cl} 3$ & $0.98078(10)$ & $0.50596(4)$ & $0.25670(5)$ & $0.0559(2)$ \\
\hline $\mathrm{Cl} 4$ & $0.16551(14)$ & $0.98789(4)$ & $0.39746(5)$ & $0.0602(2)$ \\
\hline N1 & $0.6389(2)$ & $0.77422(9)$ & $0.47038(12)$ & $0.0220(4)$ \\
\hline N2 & $0.4981(3)$ & $0.66045(9)$ & $0.42577(13)$ & $0.0237(4)$ \\
\hline $\mathrm{C} 1$ & $0.8256(3)$ & $0.66250(12)$ & $0.57962(17)$ & $0.0293(5)$ \\
\hline $\mathrm{H} 1 \mathrm{~A}$ & 0.9052 & 0.6991 & 0.5846 & $0.035^{*}$ \\
\hline H1B & 0.8487 & 0.6368 & 0.6354 & $0.035^{\star}$ \\
\hline $\mathrm{C} 2$ & $0.8653(3)$ & $0.62366(12)$ & $0.50031(18)$ & $0.0274(5)$ \\
\hline C3 & $0.9441(3)$ & $0.65035(13)$ & $0.42807(17)$ & $0.0295(6)$ \\
\hline H3 & 0.9741 & 0.6939 & 0.4302 & $0.035^{\star}$ \\
\hline $\mathrm{C} 4$ & $0.9793(3)$ & $0.61458(14)$ & $0.35337(18)$ & $0.0347(6)$ \\
\hline H4 & 1.0346 & 0.6332 & 0.3051 & $0.042^{*}$ \\
\hline $\mathrm{C} 5$ & $0.9331(3)$ & $0.55163(14)$ & $0.35000(19)$ & $0.0361(6)$ \\
\hline C6 & $0.8530(3)$ & $0.52352(14)$ & $0.4196(2)$ & $0.0403(7)$ \\
\hline H6 & 0.8211 & 0.4801 & 0.4163 & $0.048^{*}$ \\
\hline $\mathrm{C} 7$ & $0.8204(3)$ & $0.55973(13)$ & $0.4940(2)$ & $0.0357(6)$ \\
\hline $\mathrm{H} 7$ & 0.7659 & 0.5406 & 0.5421 & $0.043^{*}$ \\
\hline $\mathrm{C} 8$ & $0.3035(3)$ & $0.73429(11)$ & $0.57325(16)$ & $0.0245(5)$ \\
\hline $\mathrm{H} 8 \mathrm{~A}$ & 0.2244 & 0.7033 & 0.5412 & $0.029^{*}$ \\
\hline H8B & 0.2731 & 0.7367 & 0.6369 & $0.029^{\star}$ \\
\hline C9 & $0.2704(3)$ & $0.79740(11)$ & $0.53029(16)$ & $0.0234(5)$ \\
\hline C10 & $0.2932(3)$ & $0.85329(12)$ & $0.58044(16)$ & $0.0270(5)$ \\
\hline $\mathrm{H} 10$ & 0.3307 & 0.8510 & 0.6434 & $0.032^{*}$ \\
\hline C11 & $0.2624(4)$ & $0.91181(13)$ & $0.54036(17)$ & $0.0332(6)$ \\
\hline H11 & 0.2767 & 0.9495 & 0.5753 & $0.040^{\star}$ \\
\hline C12 & $0.2103(4)$ & $0.91449(12)$ & $0.44805(18)$ & $0.0338(6)$ \\
\hline C13 & $0.1897(3)$ & $0.86048(13)$ & $0.39608(16)$ & $0.0293(5)$ \\
\hline H13 & 0.1553 & 0.8632 & 0.3328 & $0.035^{\star}$ \\
\hline C14 & $0.2197(3)$ & $0.80247(11)$ & $0.43712(17)$ & $0.0245(5)$ \\
\hline H14 & 0.2058 & 0.7651 & 0.4015 & $0.029^{\star}$ \\
\hline C15 & $0.7005(3)$ & $0.83109(12)$ & $0.49631(17)$ & $0.0290(5)$ \\
\hline H15 & 0.7154 & 0.8406 & 0.5594 & $0.035^{\star}$ \\
\hline C16 & $0.7434(4)$ & $0.87653(13)$ & $0.4348(2)$ & $0.0368(6)$ \\
\hline H16 & 0.7898 & 0.9162 & 0.4551 & $0.044^{\star}$ \\
\hline C17 & $0.7174(4)$ & $0.86304(13)$ & $0.3438(2)$ & $0.0408(7)$ \\
\hline H17 & 0.7455 & 0.8935 & 0.3000 & $0.049^{\star}$ \\
\hline C18 & $0.6503(4)$ & $0.80501(12)$ & $0.31598(19)$ & $0.0339(6)$ \\
\hline H18 & 0.6292 & 0.7957 & 0.2530 & 0.041 * \\
\hline C19 & $0.6136(3)$ & $0.76016(11)$ & $0.38062(15)$ & $0.0227(5)$ \\
\hline $\mathrm{C} 20$ & $0.5476(3)$ & $0.69619(11)$ & $0.35705(16)$ & $0.0219(5)$ \\
\hline $\mathrm{C} 21$ & $0.5388(3)$ & $0.67292(13)$ & $0.26900(16)$ & $0.0301(5)$ \\
\hline $\mathrm{H} 21$ & 0.5729 & 0.6985 & 0.2208 & $0.036^{\star}$ \\
\hline $\mathrm{C} 22$ & $0.4795(3)$ & $0.61185(14)$ & $0.25209(17)$ & $0.0336(6)$ \\
\hline $\mathrm{H} 22$ & 0.4758 & 0.5949 & 0.1923 & $0.040^{*}$ \\
\hline $\mathrm{C} 23$ & $0.4262(3)$ & $0.57587(13)$ & $0.32175(18)$ & $0.0340(6)$ \\
\hline $\mathrm{H} 23$ & 0.3828 & 0.5343 & 0.3110 & $0.041^{*}$ \\
\hline C24 & $0.4377(3)$ & $0.60198(12)$ & $0.40811(18)$ & $0.0307(6)$ \\
\hline H24 & 0.4012 & 0.5774 & 0.4568 & $0.037^{\star}$ \\
\hline
\end{tabular}

bipy-H), 9.09-9.11 (d, 1H, bipy-H). ${ }^{13} \mathbf{C}\left\{{ }^{1} \mathbf{H}\right\} \mathbf{N M R}\left(\mathrm{CDCl}_{3}, \mathrm{ppm}\right)$ : $\delta 50.4\left(\mathrm{CH}_{2}\right), 127.3,129.1,129.8,138.2(\mathrm{Ph}-\mathrm{C}), 121.0,126.6,127.0$, 140.6, 148.5 (bipy-C).

\section{Experimental details}

The C-bound $\mathrm{H}$ atoms were geometrically placed $(\mathrm{C}-\mathrm{H}=0.95-0.99 \AA)$ and refined as riding with $U_{\text {iso }}(\mathrm{H})=$ $1.2 U_{\text {eq }}(\mathrm{C})$.

\section{Comment}

In connection with the recent report of the crystal and molecular structures of (4- $\left.\mathrm{BrC}_{6} \mathrm{H}_{4}\right)_{2} \mathrm{SnBr}_{2}$ (2,2'-bipyridyl) [6], herein the synthesis and structure of the all-chloro derivative, (I), are described. The molecule of (I) is illustrated in the figure $(50 \%$ displacement ellipsoids). A distorted octahedral geometry for the tin atom is noted which is based on a $\mathrm{C}_{2} \mathrm{Cl}_{2} \mathrm{~N}_{2}$ donor set defined by two carbon atoms of the 4-chloro-substituted benzyl groups, two chloride atoms and two nitrogen atoms of the 2,2'-bipyridyl molecule. The benzyl-carbon atoms are mutually trans, and each of the chloride atoms is trans to a pyridylnitrogen atom. The $\mathrm{Sn}-\mathrm{Cl}$ bond lengths are experimentally equivalent [ $\mathrm{Sn}-\mathrm{Cl} 1=2.5093(6) \AA \AA$ and $\mathrm{Sn}-\mathrm{Cl} 2=2.5094(6) \AA]$ as are the $\mathrm{Sn}-\mathrm{N}$ bonds $[\mathrm{Sn}-\mathrm{N} 1=2.3439(19) \AA$ and $\mathrm{Sn}-$ $\mathrm{N} 2=2.3478(19) \AA]$. This contrasts the situation found in the all-bromo derivative where non-systematic differences in tinligand bond lengths were noted [6]. Such variations have been proven by DFT methods on related compounds to be dependent upon global molecular packing effects in crystals [7, 8].

In (I), the five-membered chelate ring formed by the 2,2'-bipyridyl ligand is responsible for the greatest distortion from the ideal octahedral geometry with the acute N1-Sn$\mathrm{N} 2$ chelate angle being $70.25(7)^{\circ}$. The maximum deviation of a trans angles is seen in the N1- $\mathrm{Sn}-\mathrm{Cl} 2$ angle of $163.73(5)^{\circ}$. As reported for the all-bromo derivative [6], the benzyl-phenyl rings are orientated to lie over the $2,2^{\prime}$-bipyridyl molecule. In the present case, the separation between the ring centroids of the chelate and C2-phenyl rings is 3.7784(14) $\AA$; the separation between the N1-pyridyl and C9-phenyl rings is marginally longer at 3.7957(15) Å. Recent literature has highlighted the stabilising effect of $\pi \cdots \pi$ interactions where at least one of the rings is a chelate ring $[9,10]$.

The structure of the $\left(4-\mathrm{ClC}_{6} \mathrm{H}_{4} \mathrm{CH}_{2}\right)_{2} \mathrm{SnCl}_{2}$ precursor molecule is available in the literature for comparison [11]. The independent $\mathrm{Sn}-\mathrm{Cl}$ bond length in this 2-fold symmetric structure is 2.3754(11) Å which is considerably shorter than those reported above for the title compound, reflecting, in part, the increased coordination number for tin.

While the precursor $\left(4-\mathrm{XC}_{6} \mathrm{H}_{4} \mathrm{CH}_{2}\right)_{2} \mathrm{SnX} \mathrm{X}_{2}, \quad \mathrm{X}=\mathrm{Cl}$ [11] and $\mathrm{Br}$ [12] species are isostructural, those of (4$\left.\mathrm{XC}_{6} \mathrm{H}_{4} \mathrm{CH}_{2}\right)_{2} \mathrm{SnX}_{2}\left(2,2^{\prime}\right.$-bipyridyl), $\mathrm{X}=\mathrm{Cl}$ and $\mathrm{Br}$ [6], are not. However, the title compound appears to be isostructural with the 1,10-phenanthroline analogue [13]. The non-isostructural relationship between the (4- $\left.\mathrm{XC}_{6} \mathrm{H}_{4} \mathrm{CH}_{2}\right)_{2} \mathrm{SnX}_{2}\left(2,2^{\prime}\right.$-bipyridyl), $\mathrm{X}=\mathrm{Cl}$ and $\mathrm{Br}$ [6], compounds is reflected in the distinctive atom-to-atom points of contact between molecules. 
Based on the distance criteria in PLATON [14], the only significant intermolecular interactions in the crystal are benzyl- and pyridyl- $\mathrm{C}-\mathrm{H} \cdots \mathrm{Cl}$ (tin- and phenylbound) interactions $\left[\mathrm{C} 4-\mathrm{H} 4 \cdots \mathrm{Cl}^{1}{ }^{\mathrm{i}}: \mathrm{H} 4 \cdots \mathrm{Cl}^{\mathrm{i}}=2.77 \AA\right.$, $\mathrm{C} 4 \cdots \mathrm{Cl}^{\mathrm{i}}=3.642(3) \AA$ with angle at $\mathrm{H} 4=153^{\circ}$, and $\mathrm{C} 22-$ $\mathrm{H} 22 \cdots \mathrm{Cl} 4^{\mathrm{ii}}: \mathrm{H} 22 \cdots \mathrm{Cl} 4^{\mathrm{ii}}=2.80 \AA \mathrm{A}, \mathrm{C} 22 \cdots \mathrm{Cl} 4^{\mathrm{ii}}=3.545(3) \AA$ with angle at $\mathrm{H} 22=136^{\circ}$ for symmetry operations (i) $1 / 2+\mathrm{x}$, $3 / 2-y,-1 / 2+z$ and (ii) $1 / 2-x,-1 / 2+y, 1 / 2-z]$. The molecules pack in columns aligned along the $a$-axis direction and with each molecule accepting and donating two C$\mathrm{H}$. . Cl interactions, a three-dimensional architecture ensues.

Finally, an analysis of the calculated Hirshfeld surfaces was undertaken in order to evaluate the molecular packing further and to make a comparison with the packing in the crystal of the all-bromo analogue [6]. For this purpose, Crystal Explorer 17 [15] was employed following protocols established in the literature [16] to calculate the Hirshfeld surfaces and two-dimensional fingerprint plots (overall and delineated into specific contacts). In the crystal, $\mathrm{H} \cdots \mathrm{H}$ contacts make the greatest overall contribution at $42.3 \%$, being greater than $\mathrm{H} \cdots \mathrm{Cl} / \mathrm{Cl} \cdots \mathrm{H}$ contacts at $38.7 \%$. Other significant contacts are noted, that is, $\mathrm{H} \cdots \mathrm{C} / \mathrm{C} \cdots \mathrm{H}[12.4 \%]$, then $\mathrm{Cl} \cdots \mathrm{C} / \mathrm{C} \cdots \mathrm{Cl}$ [3.0\%], $\mathrm{Cl} \cdots \mathrm{Cl}[2.2 \%]$ and $\mathrm{C} \cdots \mathrm{C}[2.0 \%]$. A very similar pattern in surface contacts were calculated for the all-bromo derivative with the notable exception that $\mathrm{H} \cdots \mathrm{Br} / \mathrm{Br} \cdots \mathrm{H}$ [40.8\%] were marginally more prevalent than $\mathrm{H} \cdots \mathrm{H}[40.2 \%]$ contacts [6].

Acknowledgements: Sunway University Sdn Bhd is thanked for financial support of this work through Grant no. STRRCTR-RCCM-001-2019.

\section{References}

1. Rigaku Oxford Diffraction: CrysAlis ${ }^{\text {PRO }}$. Rigaku Corporation, Oxford, UK (2018).

2. Sheldrick, G. M.: A short history of SHELX. Acta Crystallogr. A64 (2008) 112-122.

3. Sheldrick, G. M.: Crystal structure refinement with SHELXL. Acta Crystallogr. C71 (2015) 3-8.
4. Farrugia, L. J.: WinGX and ORTEP for Windows: an update. J. Appl. Crystallogr. 45 (2012) 849-854.

5. Sisido, K.; Takeda, Y.; Kinugawa, Z.: Direct synthesis of organotin compounds I. di- and tribenzyltin chlorides. J. Am. Chem. Soc. 83 (1961) 538-541.

6. Lee, S. M.; Lo, K. M.; Tiekink, E. R. T.: Crystal structure of (2,2'-bipyridyl)bis(4-bromobenzyl)dibromidotin(IV), $\mathrm{C}_{24} \mathrm{H}_{20} \mathrm{Br}_{4} \mathrm{~N}_{2}$ Sn. Z. Kristallogr. NCS 234 (2019) submitted, doi: org/10.1515/ncrs-2019-0507.

7. Buntine, M. A.; Hall, V. J.; Kosovel, F. J.; Tiekink, E. R. T.: Influence of crystal packing on molecular geometry: a crystallographic and theoretical investigation of selected diorganotin systems. J. Phys. Chem. A 102 (1998) 2472-2482.

8. Buntine, M. A.; Hall, V. J.; Tiekink, E. R. T.: The crystal and molecular structures of $\mathrm{R}_{2} \mathrm{SnCl}_{2}$ (1,10-phenanthroline), $\mathrm{R}=\mathrm{iPr}$, $\mathrm{Cy}, \mathrm{CH}_{2} \mathrm{Ph}$ and $\mathrm{R}_{2}=\mathrm{Me}, \mathrm{Ph}$ : a comparison between solid state and theoretical structures. Z. Kristallogr. 213 (1998) 669-678.

9. Malenov, D. P.; Janjić, G. V.; Medaković, V. B.; Hall, M. B.; Zarić, S. D.: Noncovalent bonding: stacking interactions of chelate rings of transition metal complexes. Coord. Chem. Rev. 345 (2017) 318-341.

10. Tiekink, E. R. T.: Supramolecular assembly based on "emerging" intermolecular interactions of particular interest to coordination chemists. Coord. Chem. Rev. 345 (2017) 209-228.

11. Kuang, D.-Z.; Feng, Y.-L.: Synthesis and crystal structure of bis(p-chlorobenzyl)tin dichloride. Chin. J. Inorg. Chem. 16 (2000) 603-606.

12. Lee, S. M.; Lo, K. M.; Tiekink, E. R. T.: Crystal structure of dibromidobis(4-bromobenzyl)tin(IV), $\mathrm{C}_{14} \mathrm{H}_{12} \mathrm{Br}_{4} \mathrm{Sn}$. Z. Kristallogr. NCS 234 (2019) 947-948.

13. Tan, C. L.; Lo, K. M.; Ng, S. W.: Dichloridobis(4-chloro-benzylКC)(1,10-phenanthroline- $\left.\mathrm{K}^{2} N, N^{\prime}\right) \operatorname{tin}(\mathrm{IV})$. Acta Crystallogr. E65 (2009) m717.

14. Spek, A. L.: Structure validation in chemical crystallography. Acta Crystallogr. D65 (2009) 148-155.

15. Turner, M. J.; McKinnon, J. J.; Wolff, S. K.; Grimwood, D. J.; Spackman, P. R.; Jayatilaka, D.; Spackman, M. A.: Crystal Explorer v17. The University of Western Australia, Australia (2017.)

16. Tan, S. L.; Jotani, M. M.; Tiekink, E. R. T.: Utilizing Hirshfeld surface calculations, non-covalent interaction $(\mathrm{NCl})$ plots and the calculation of interaction energies in the analysis of molecular packing. Acta Crystallogr. E75 (2019) 308-318. 